\title{
Surface Modification of Electrodes for Amperometric Biosensors in Analytical Chemistry ${ }^{\dagger}$
}

\author{
Shaojun Dong \\ Laboratory of Electroanalytical Chemistry, Changchun Institute of Applied Chemistry, \\ Chinese Academy of Sciences, Changchun, 130022, China
}

\begin{abstract}
Amperometric biosensors based on surface modifications of electrodes are described. Cobalt porphyrins modified on glassy carbon and carbon fiber electrodes can greatly decrease the overpotential and increase the sensitivity of detection due to EC electrocatalysis. Cation exchange polymer films, Nafion and Eastman Kodak AQ, as well as poly(1,2diaminobenzene) film, were used as membrane barriers; they can avoid the interference from ascorbic acid and uric acid. Simple ferrocene without any substitutes was incorporated in Nafion film for preparation of glucose sensor; it shows long term stability because of two domains (hydrophilic and hydrophobic) existed in the film. By using ferrocene derivatives as mediator, amino acid enzyme electrode was fabricated with double-enzymes. Dehydrogenase (lactic acid, alcohol and malic acid dehydrogenase) enzyme electrodes were prepared with double-mediators. This kind of biosensor can overcome the disadvantage of poor selectivity and reproducibility by using the mediators for direct determination of NADH.
\end{abstract}

Keywords Chemically modified electrode, metalloporphyrin, amperometric biosensor, ferrocene, oxidase enzyme electrode dehydrogenase enzyme electrode

Amperometric biosensors continue to be a field of interesting research in analytical chemistry. Many significant developments have been made in this field, especially the progress of miniaturization of transducers and molecular design of the electrode surface. This paper describes some new results of amperometric biosensors based on the surface modification of electrodes. ${ }^{1-8}$

\section{Increasing sensitivity}

It is well-known that a glucose oxidase enzyme electrode is based on the enzyme catalytic reaction:

$$
\text { glucose }+\mathrm{O}_{2}+\mathrm{H}_{2} \mathrm{O} \stackrel{\text { GOD }}{\longrightarrow} \text { gluconic acid }+\mathrm{H}_{2} \mathrm{O}_{2} \text {. }
$$

One must determine glucose by measuring either the consumption of oxygen or the production of hydrogen peroxide. A disadvantage may occur due to high over-potential and less sensitive response if a metal or carbon electrode is used. We have used modifications of metalloporphyrins on glassy carbon electrode and carbon fiber microelectrode in glucose sensors ${ }^{1,2}$ and microsensors. These procedures greatly decrease the overpotential and increase the sensitivity of detections based on EC electrocatalysis. For example, CoTPP/ GC chemically modified glassy carbon (GC) electrode

\footnotetext{
† Presented at the ASIANALYSIS II, August 9-13, 1993, Changchun, China.
}

(CME) has been used as an oxygen electrode by the electrocatalysis of dioxygen reduction (EC) for enzyme electrode to elevate the sensitivity, according to the following scheme:

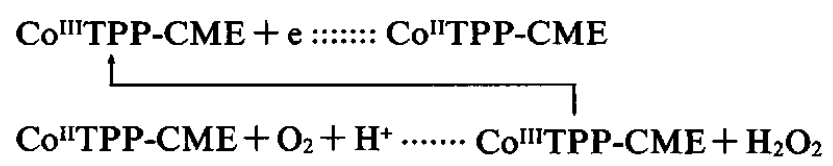

By heat treatment of the metalloporphyrin-modified electrode with incorporation of GOD, the resulting glucose sensors show high activity and stability. Another example corresponds to the glucose sensor based on Pd particles deposited on glassy carbon electrode $(\mathrm{Pd} / \mathrm{GCE})^{3}$, as shown in Fig. 1. The current response of hydrogen peroxide is much higher at $\mathrm{Pd}$ / GCE and GOD-Pd/GCE (curve B and C) than that at bake GCE (curve $A$ ), which indicates the increase of sensitivity.

\section{Enhancing selectivity}

Cation-exchange polymer films (Nafion, Eastman Kodak AQ) were used on surface modification in glucose sensors. They can act as a membrane barrier avoiding interference from electroactive anions, such as ascorbic acid and uric acid in application of sensors. For example, GOD/CoTMPyP-Nafion/CF electrode has been fabricated (TMPyP, tetramethyl pyridyl; CF, carbon fiber). Electrodepositing platinum particle on 


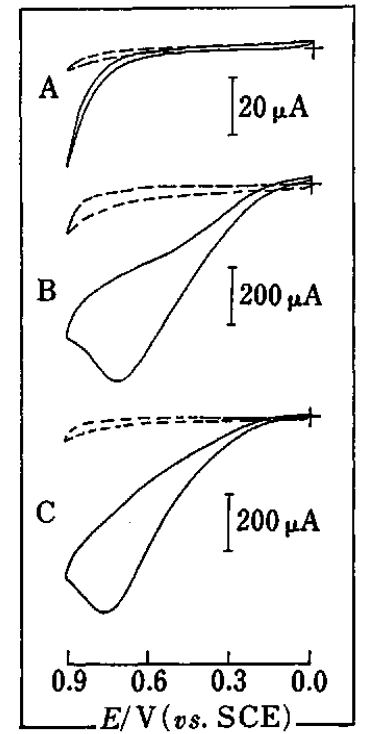

Fig. 1 Cyclic voltammograms for $2.5 \times 10^{-2} \mathrm{M}$ hydrogen peroxide at the (A) bare GCE, (B) Pd/GCE and (C) GOD$\mathrm{Pd} / \mathrm{GCE}$. The dashed lines indicate the response of the blank solution. Scan rate, $50 \mathrm{mV} \mathrm{s}^{-1}, 0.1 \mathrm{M}$ phosphate buffer solution ( $\mathrm{pH} 7.2)$.

Table 1 The selectivity of the glucose biosensor based on poly(1,2-diaminobenzene) (PDAB) film GCE with deposited Pt particle

\begin{tabular}{lcc}
\hline \multicolumn{1}{c}{ Reagent } & \multicolumn{2}{c}{ Relative value of current response } \\
& Pt deposited & $\begin{array}{c}\text { Pt deposited GCE } \\
\text { coated with PDAB }\end{array}$ \\
\hline $\mathrm{H}_{2} \mathrm{O}_{2}$ & 100.0 & 100.0 \\
Ascorbic acid & 81.5 & 1.5 \\
Uric acid & 88.0 & 2.0 \\
\hline
\end{tabular}

Nafion film is another approach to increase sensitivity of oxygen and hydrogen peroxide measurement with good selectivity and anti-interference. In this way, GOD/PtCoTMPyP-Nafion/CF array electrode and GOD/Pt$\mathrm{AQ} / \mathrm{GC}$ electrode have been used for glucose sensors.

A poly(1,2-diaminobenzene) film modified on platinum electrode with GOD was prepared, i.e. GOD/P$\mathrm{DAB} / \mathrm{Pt} / \mathrm{GC}$ electrode. It has permselectivity that allows the passage of hydrogen peroxide but prevents interference from reaching the electrode surface. The selectivity of this glucose biosensor is shown in Table $1 .{ }^{4}$ Obviously, the interferences from ascorbic acid and uric acid can be effectively removed.

\section{Microfabrication}

Microfabrication is one of the main development of biosensors. By using microelectrode it shows rapid mass transfer, small IR drop, large signal to noise ratio. For example, besides CF and CF array electrodes prepared as shown above, we have prepared miniaturized enzyme modified electrode ${ }^{1,5}$ GOD/CoTPP/CF cylinder electrode which exhibits anti-interference and rapid response, and is stable and available for in vivo analysis. The advantage of microelectrode array is that it behaves like a microelectrode.

\section{Mediation}

Mediator enzyme electrode belongs to second generation enzyme electrode. Previous amperometric biosensors (Clark type) utilize redox enzyme (e.g. GOD), where oxygen is electron acceptor. Oxygen dessolution and fluctuation may occur as the disadvantage of this kind of biosensor. If oxygen can be replaced by a mediator the dynamic linear range may be extended, while the working electrode potential and the interference may be decreased. Usual mediators used are ferrocene and its derivatives: methyl viologens, benzoquinones, etc. Because of the large solubility of $\mathrm{Fc}^{+}$ (oxidized state of $\mathrm{Fc}$ ) in water, the $\mathrm{Fc}$ may be lost, this makes the enzyme electrode unstable. This difficulty can be overcome by chemically modified methods. Nafion is used to fix $\mathrm{Fc}$ to prevent the loss of $\mathrm{Fc}^{+}$with the characteristics of anti-interference high sensitivity and extended dynamic linear range. Because of two domains of Nafion: hydrophilic domain and hydrophobic domain, simple ferrocene without any substitutes was incorporated in Nafion film. ${ }^{6}$ The prepared glucose sensor shows long term stability, since the oxidized form of $\mathrm{Fc}$, i.e. $\mathrm{Fc}^{+}$will not be dissolved but can be kept in the film due to the hydrophilic domain of Nafion. This is a simple, sensitive mediated type GOD enzyme electrode: written as GOD/Fc-Nafion/GC. Another cationic exchange polymer, Eastman Kodak AQ, can be used with the effect as Nafion in the biosensor. ${ }^{\mathrm{S}}$

Other examples are shown below, based on the results from our laboratory.

Amino acid enzyme electrode ${ }^{2}$ (double enzyme) system (redox enzyme) with mediator immobilized with AQ: Damino acid oxidase $+1,1^{\prime}$-bis ( $\alpha$-hydroxy ethyl)ferrocene $(\mathrm{BHFc}) \mathrm{AQ} / \mathrm{GC}+$ horseradish peroxidase

$$
\begin{aligned}
& \text { D-amino acid }+\mathrm{O}_{2} \underset{\text { oxidase }}{\stackrel{\text { D-amino acid }}{\longrightarrow}} \mathrm{H}_{2} \mathrm{O}_{2}++\mathrm{NH}_{3} \\
&+\alpha \text {-ketonic acid }
\end{aligned}
$$

$$
\begin{aligned}
& \mathrm{H}_{2} \mathrm{O}_{2}+\underset{\text { BHFc } \frac{\text { horseradish }}{\text { peroxidase }}}{\mathrm{BHFc}} \mathrm{H}_{2} \mathrm{O}+\mathrm{BHFc}^{+} \\
& \mathrm{BHFc}^{+}+\mathrm{e} \frac{\text { electrode reaction }}{+0.18 \mathrm{~V}(\text { vs. SCE })} \mathrm{BHFc}
\end{aligned}
$$

Generally, D-amino acid oxidase can not react directly with ferrocene. In our laboratory, we use a double enzyme system. Eastman AQ was used to immobilize double enzyme and BHFc with anti-interference character.

Dehydrogenase electrode/GC+double mediator system: ${ }^{2}$ lactic acid or alcohol dehydrogenase (LDH, $\mathrm{ADH})$ electrode $+\mathrm{Fe}(\mathrm{CN})_{6}{ }^{3-14-}$ mediator $+N$-PMS mediator ( $N$-methyl-phenazonium sulfate) 


$$
\mathrm{CH}_{3} \mathrm{CH}_{2} \mathrm{OH}+\mathrm{NAD} \stackrel{\mathrm{ADH}}{\rightleftharpoons} \mathrm{CH}_{3} \mathrm{CHO}+\mathrm{NADH}+\mathrm{H}^{+}
$$

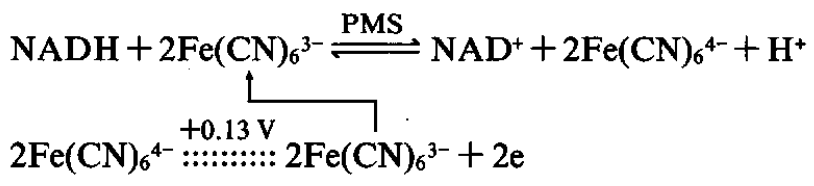

Under the action of ADH, alcohol is first oxidized to aldehyde to form NADH, then oxidized to $\mathrm{NAD}^{+}$by $\mathrm{K}_{3} \mathrm{Fe}(\mathrm{CN})_{6}$ in the presence of PMS. The chemically regenerated $\mathrm{NAD}^{+}$can continue an enzyme catalytic reaction. The formed $\mathrm{Fe}(\mathrm{CN})_{6}{ }^{4-}$ can be oxidized at the electrode surface; the produced anodic current is dependent of the concentration of alcohol.

Malic dehydrogenase (MDH)/GC enzyme system with double mediator:

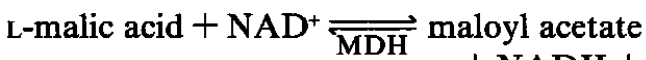

$$
\begin{aligned}
& +\mathrm{NADH}+\mathrm{H}^{+} \\
& \begin{array}{l}
\mathrm{NADH}+\mathrm{Fe}(\mathrm{CN})_{6}{ }^{3-} \longrightarrow \mathrm{NAD}^{+}+\mathrm{Fe}(\mathrm{CN})_{6} 6^{4-}+\mathrm{H}^{+} \\
\mathrm{Fe}(\mathrm{CN})_{6}{ }^{4-} \stackrel{+0.35 \mathrm{~V}}{\longrightarrow} \mathrm{Fe}(\mathrm{CN})_{6}^{3-}+\mathrm{e}
\end{array}
\end{aligned}
$$

The first reaction is going to the left side and so is not available for NADH formation. By electrochemical method, NADH can regenerate $\mathrm{NAD}^{+}$very rapidly to approach equilibrium. $\mathrm{NAD}^{+}$is the necessary auxiliary factor for dehydrogenase catalytic reaction. PMS is the catalyst which can be reduced rapidly by NADH. The formed $\mathrm{PMSH}$ can also reduce $\mathrm{Fe}(\mathrm{CN})_{6}{ }^{3-}$ rapidly;
$\mathrm{K}_{3} \mathrm{Fe}(\mathrm{CN})_{6}$ affects the magnitude of the response current; and high concentration may produce big background. Zinc ion has the doping effect for MDH, to accelerate enzyme catalytic reaction for rapid response. This kind of biosensor overcomes the disadvantage of bad selectivity and reproducibility which occur at high voltage; because of the use of mediator for indirect determination of NADH, the response time is also much more rapid than in the previous method.

This project is supported by National Science Foundation of China.

\section{References}

1. S. Dong and T. Kuwana, Electroanalysis, 3, 485 (1991).

2. X. Ji and Y. Zhang, Anal. Chem. [Chinese], 1, 267, 519, 625 (1993).

3. Q. Chi and S. Dong, Anal. Chim. Acta, 278, 17 (1993).

4. X. Ji and Y. Zhang, Chin. J. Appl. Chem., 10, 97 (1993).

5. S. Dong, M. Tian and B. Liu, Anal. Chem. [Chinese], 21, 255 (1993).

6. S. Dong, B. Wang and B. Liu, Biosensor and Bioelectronics, 7, 215 (1992).

7. S. Dong, Q. Deng and G. Cheng, Anal. Chim. Acta, 279, 235 (1993).

8. Q. Deng and S. Dong, Chem. J. Chin. Univ., 14, 1214 (1993). 